\title{
Hydrated Rubrolides from the New Zealand Tunicate Synoicum
}

\section{kuranui}

Joe Bracegirdle; Luke J. Stevenson; Abigail V. Sharrock; Michael J. Page; Jan A. Vorster; Jeremy G. Owen; David F. Ackerley; Robert A. Keyzers*

Figure S1: Underwater photo of Synoicum kuranui

Figure S2: ${ }^{1} \mathrm{H}$ NMR spectrum of $\mathbf{3}$

Figure S3: ${ }^{13} \mathrm{C}$ NMR spectrum of 3

Figure S4: COSY NMR spectrum of 3

Figure S5: HMBC NMR spectrum of 3

Figure S6: HSQC NMR spectrum of 3

Figure S7: HRESIMS of 3

Figure S8: HRESIMS/MS of 3

Figure S9: UV/Vis spectrum of 3

Figure S10: ${ }^{1} \mathrm{H}$ NMR spectrum of 5

Figure S11: COSY NMR spectrum of 5

Figure S12: HMBC NMR spectrum of 5 ........................................................................................... 9

Figure S13: HSQC NMR spectrum of 5

Figure S14: HRESIMS of 5

Figure S15: HRESIMS/MS of 5

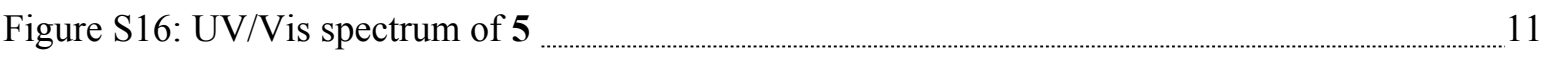

Figure S17: ${ }^{1} \mathrm{H}$ NMR spectrum of $\mathbf{6}$

Figure S18: ${ }^{13} \mathrm{C}$ NMR spectrum of 6

Figure S19: COSY NMR spectrum of 6

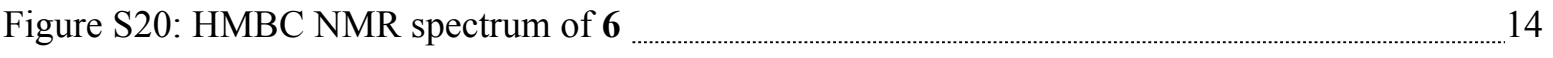

Figure S21: HSQC NMR spectrum of 6

Figure S22: HRESIMS of 6

Figure S23: HRESIMS/MS of 6

Figure S24: UV/Vis spectrum of 6

Table S1: $\mathrm{IC}_{50}$ values for compounds against HCT-116 cells. 
Figure S1 - Underwater photo of the marine tunicate Synoicum kuranui (NIWA 101543).

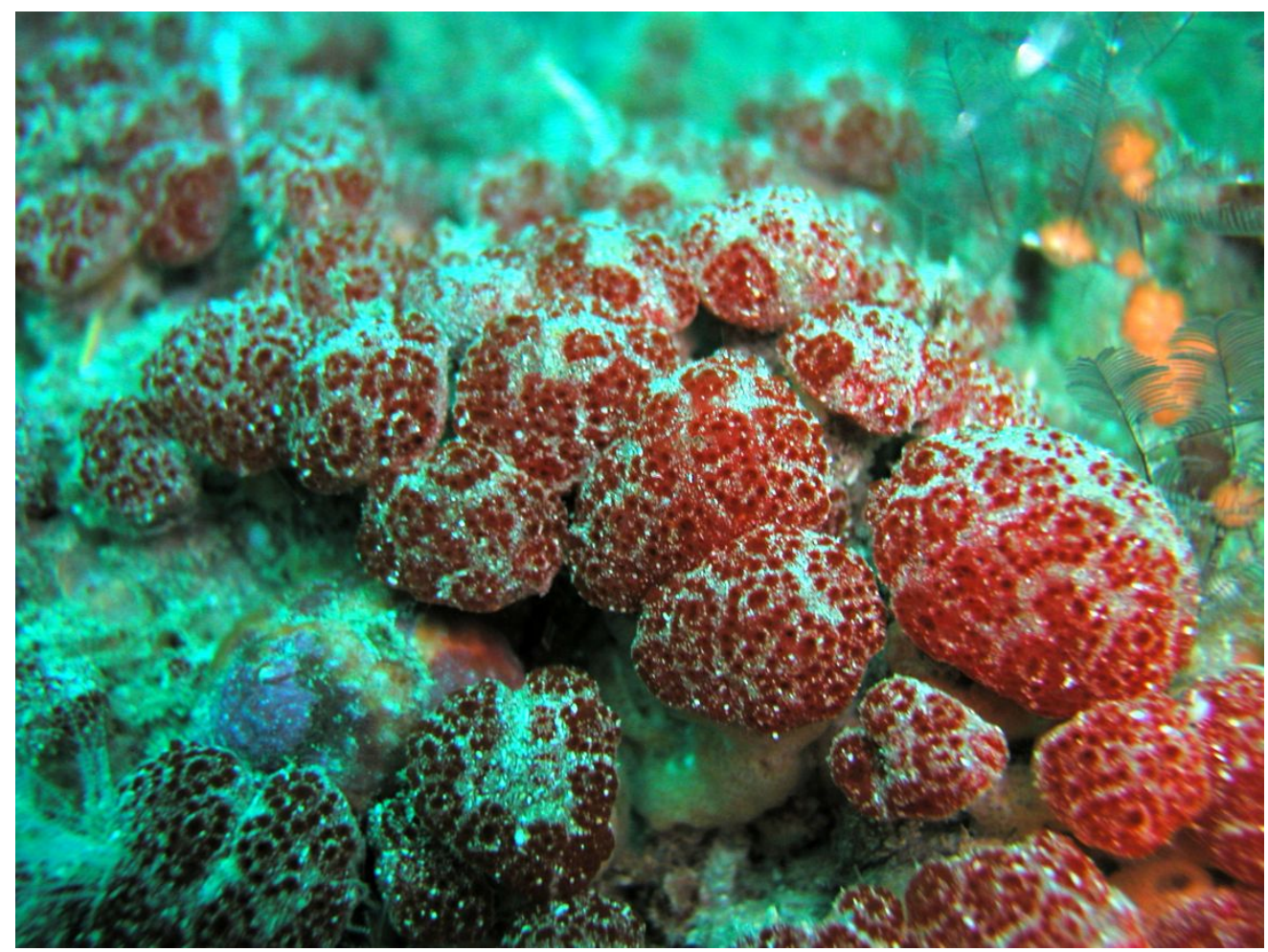


Figure S2: ${ }^{1} \mathrm{H}$ NMR spectrum $\left(600 \mathrm{MHz}, \mathrm{DMSO}-\mathrm{d}_{6}\right)$ of 3

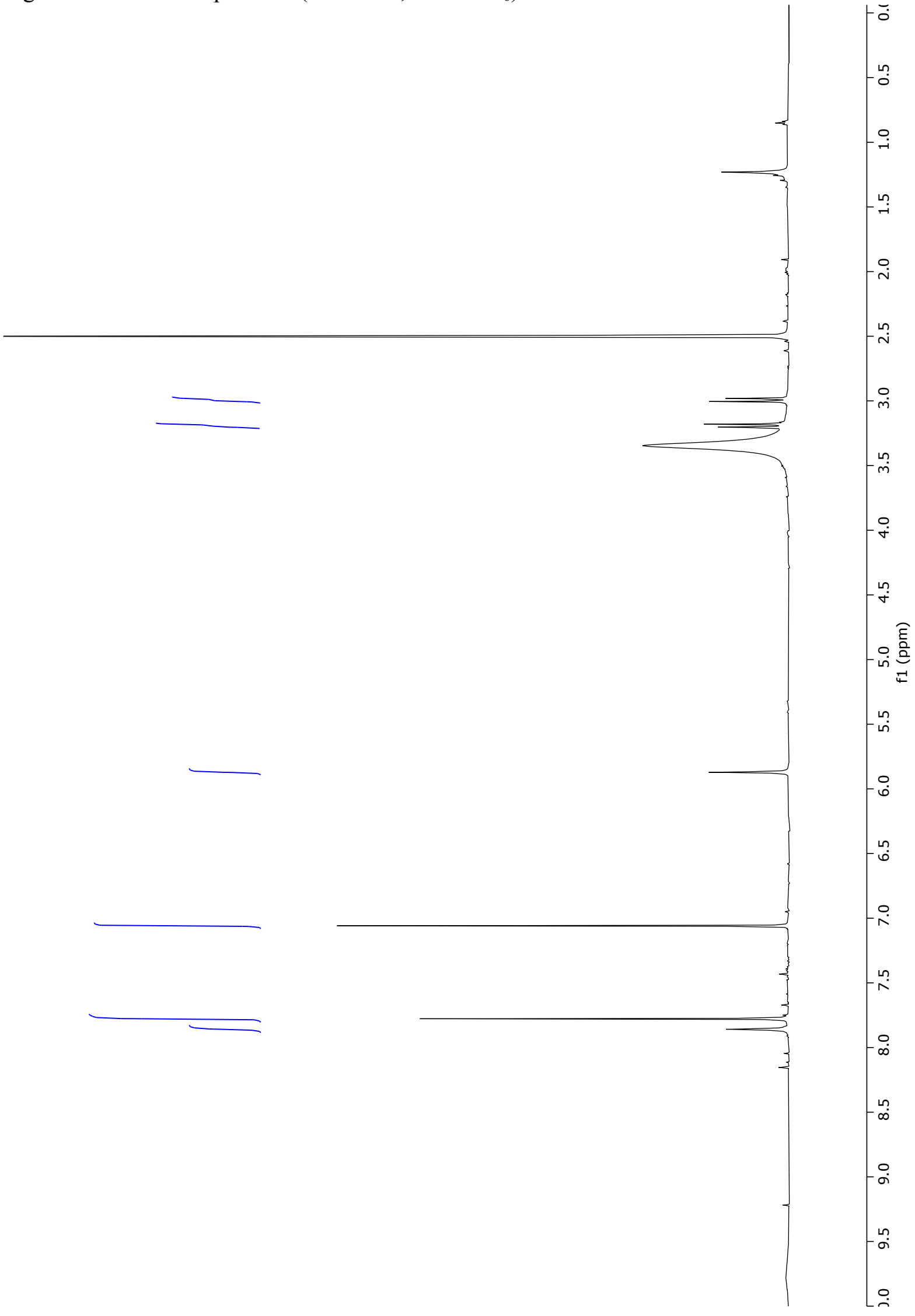


Figure S3: ${ }^{13} \mathrm{C}$ NMR spectrum (150 MHz, DMSO-d $\left.{ }_{6}\right)$ of 3

$$
\begin{aligned}
& \text { Z'90I- } \\
& \text { I'III - } \\
& \text { I'SII - }
\end{aligned}
$$

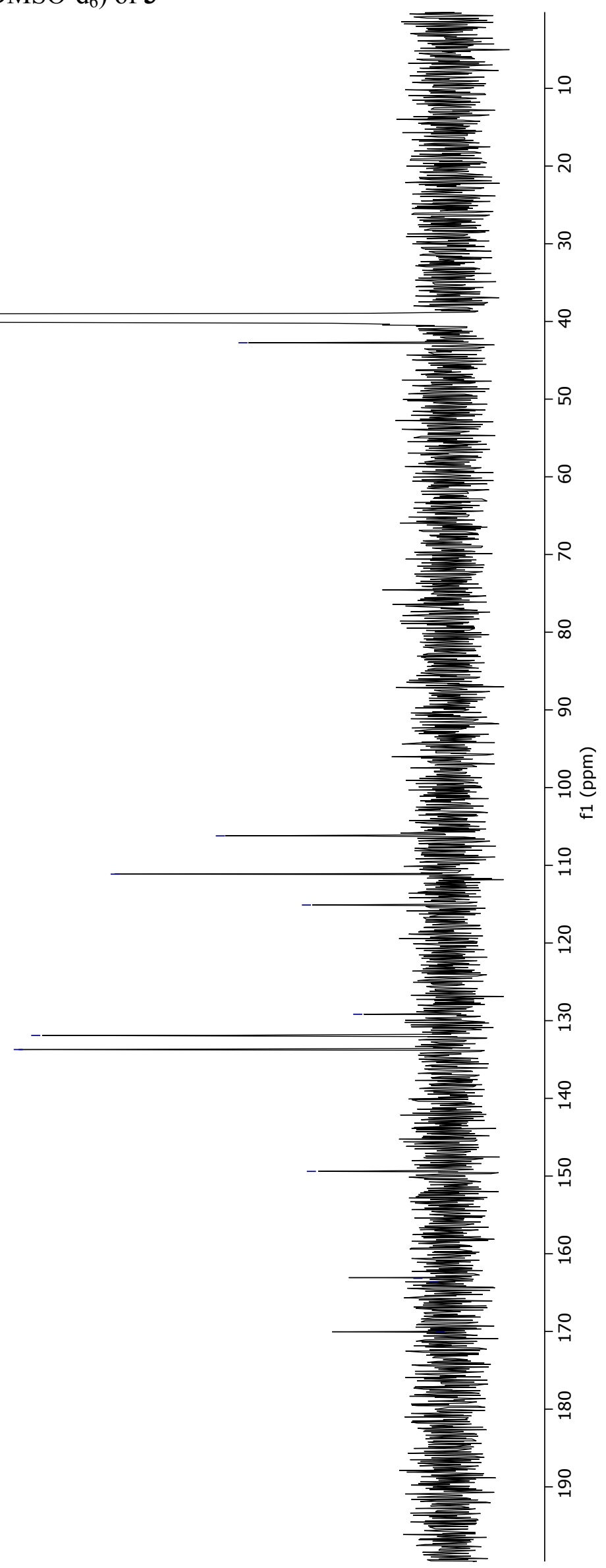


Figure S4: COSY NMR spectrum $\left(600 \mathrm{MHz}, \mathrm{DMSO}-\mathrm{d}_{6}\right)$ of 3

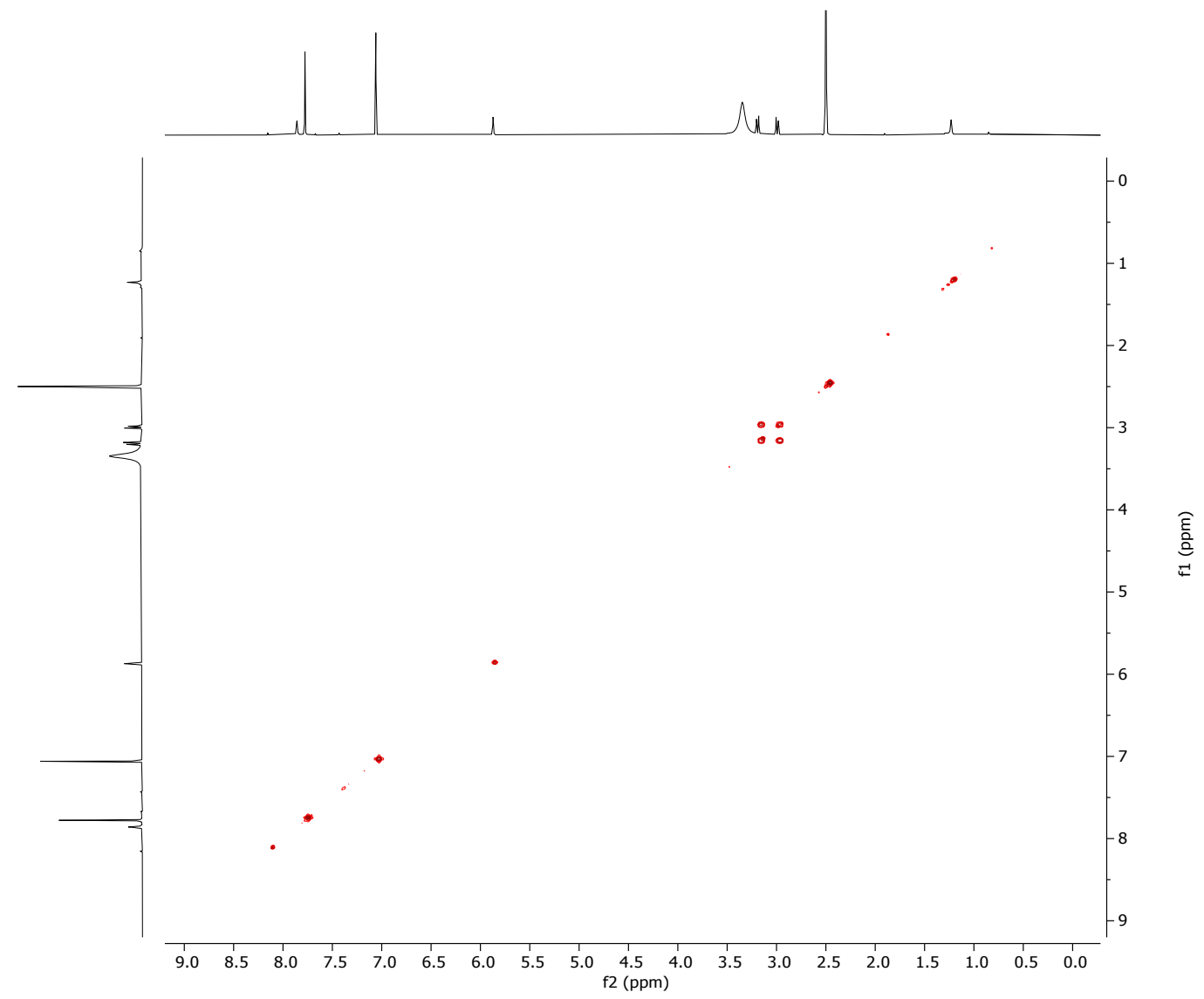

Figure S5: HMBC NMR spectrum (600 MHz, DMSO-d $\left.\mathrm{d}_{6}\right)$ of 3

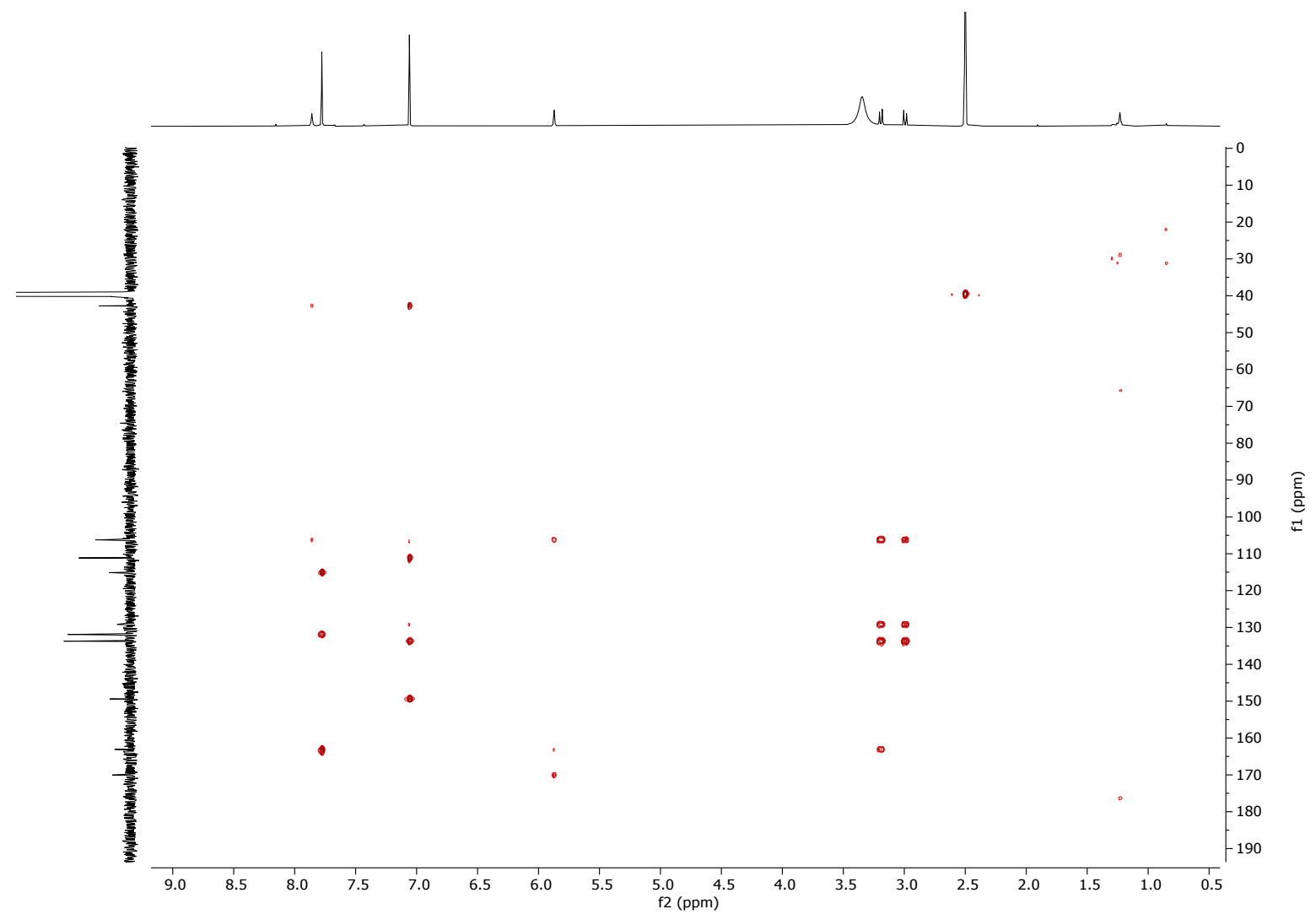


Figure S6: HSQC NMR spectrum $\left(600 \mathrm{MHz}, \mathrm{DMSO}^{\left.-\mathrm{d}_{6}\right)}\right.$ of 3

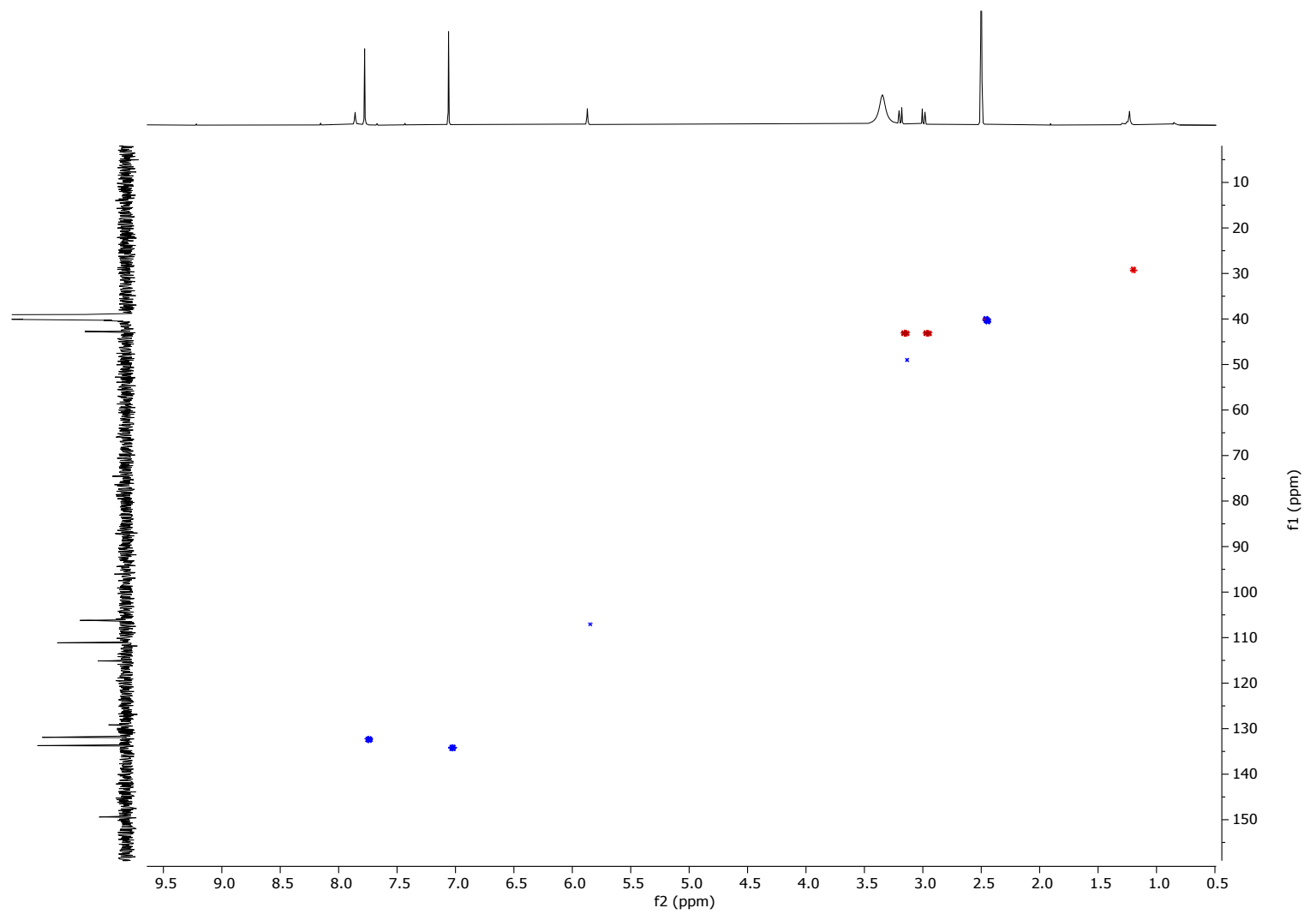

Figure S7: HRESIMS of $\mathbf{3}$
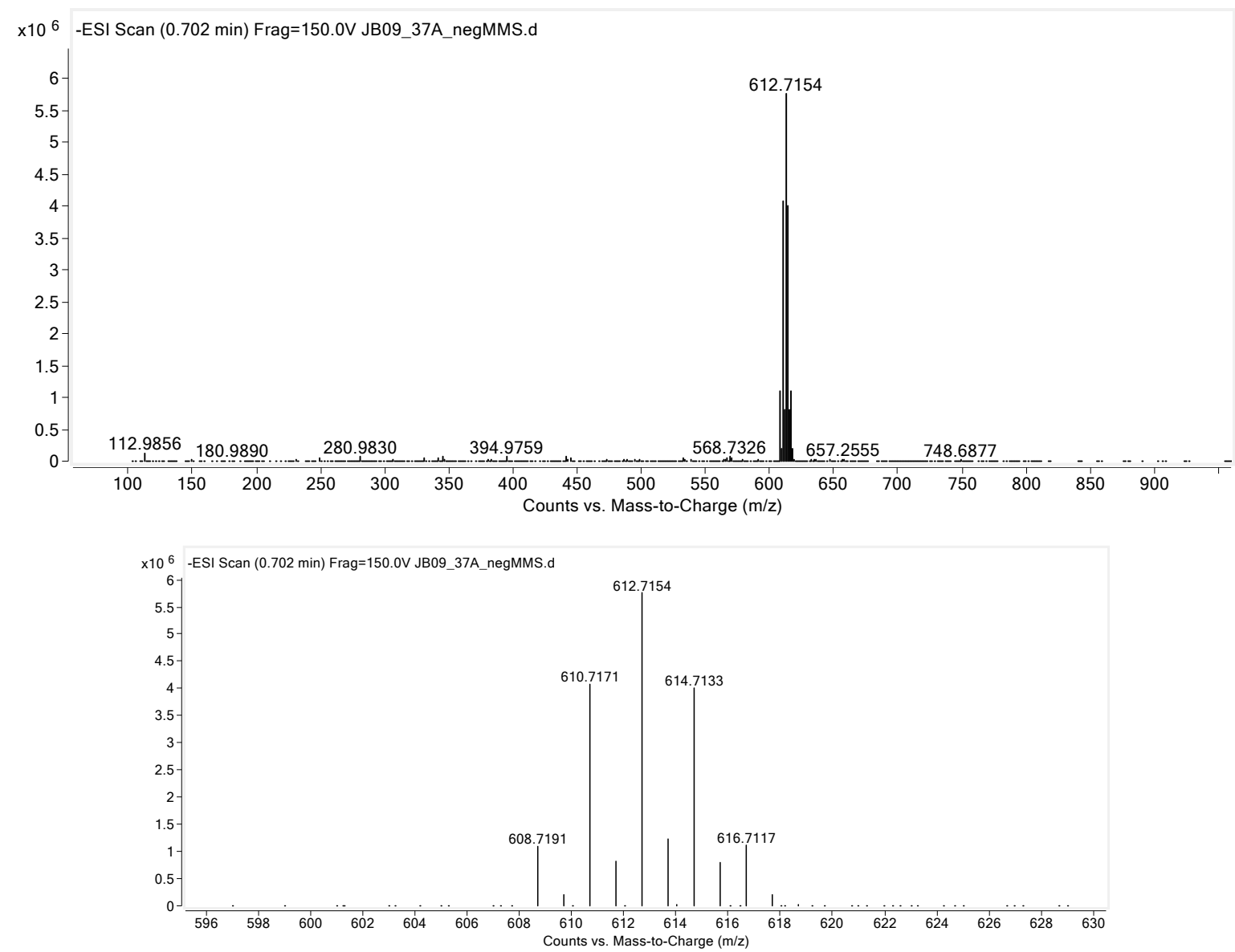
Figure S8: HRESIMS/MS of 3

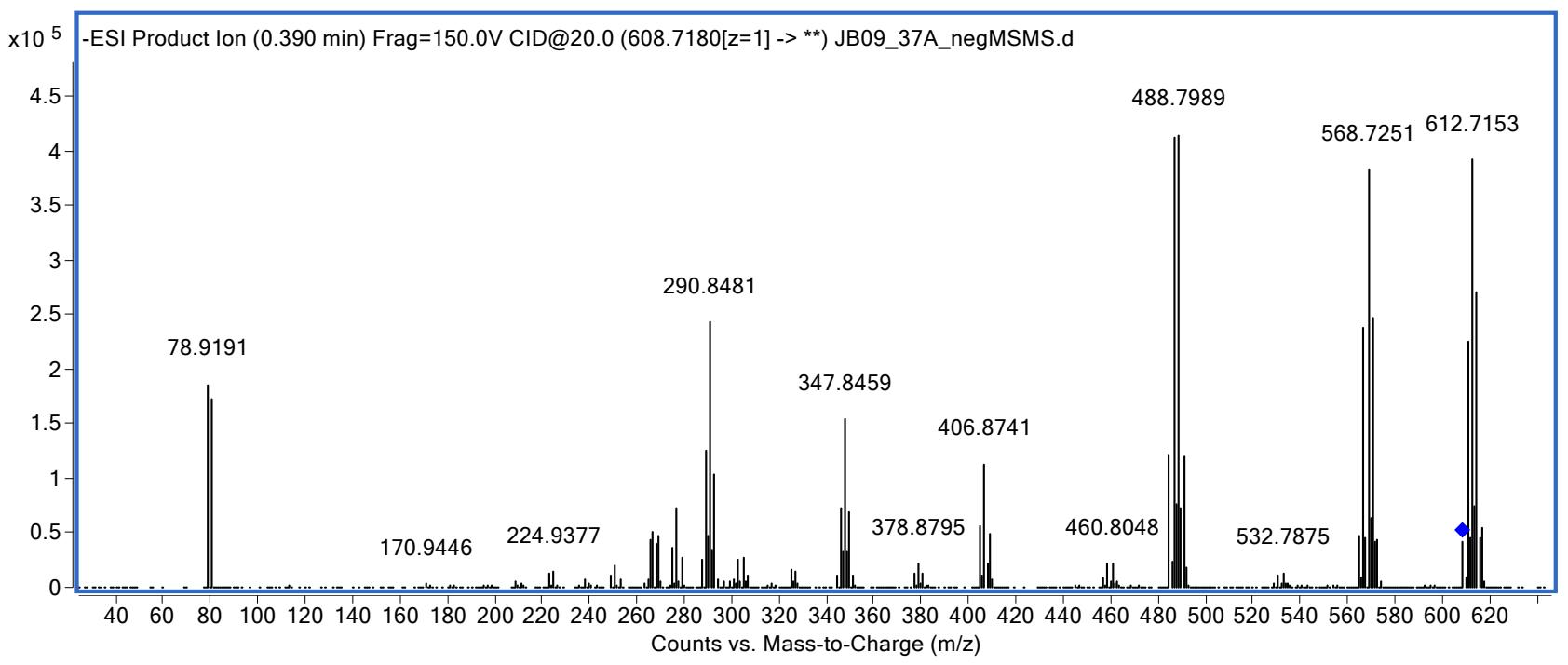

Figure S9: UV/Vis spectrum of $\mathbf{3}$

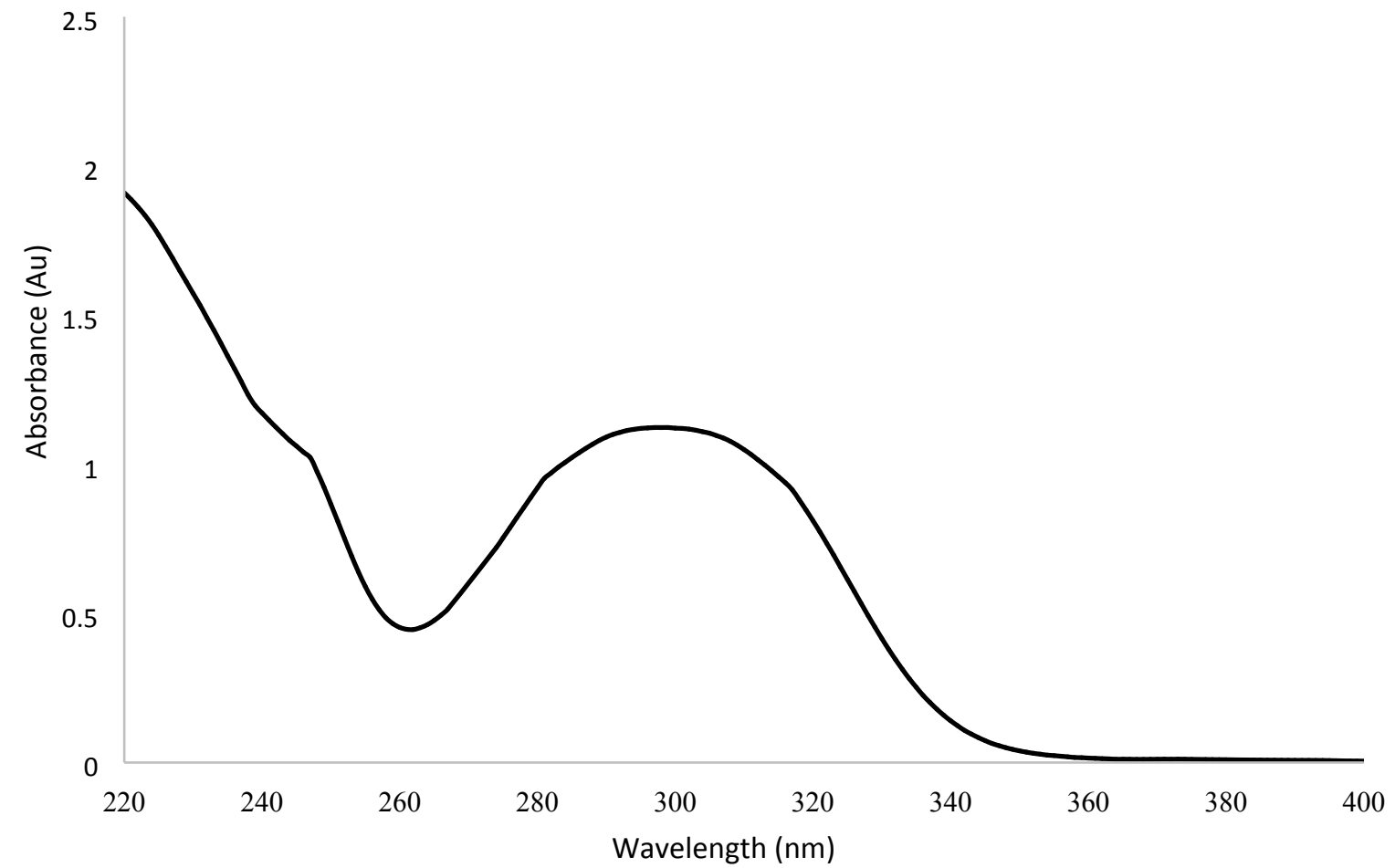


Figure S10: ${ }^{1} \mathrm{H}$ NMR spectrum $\left(600 \mathrm{MHz}, \mathrm{DMSO}-\mathrm{d}_{6}\right)$ of 5

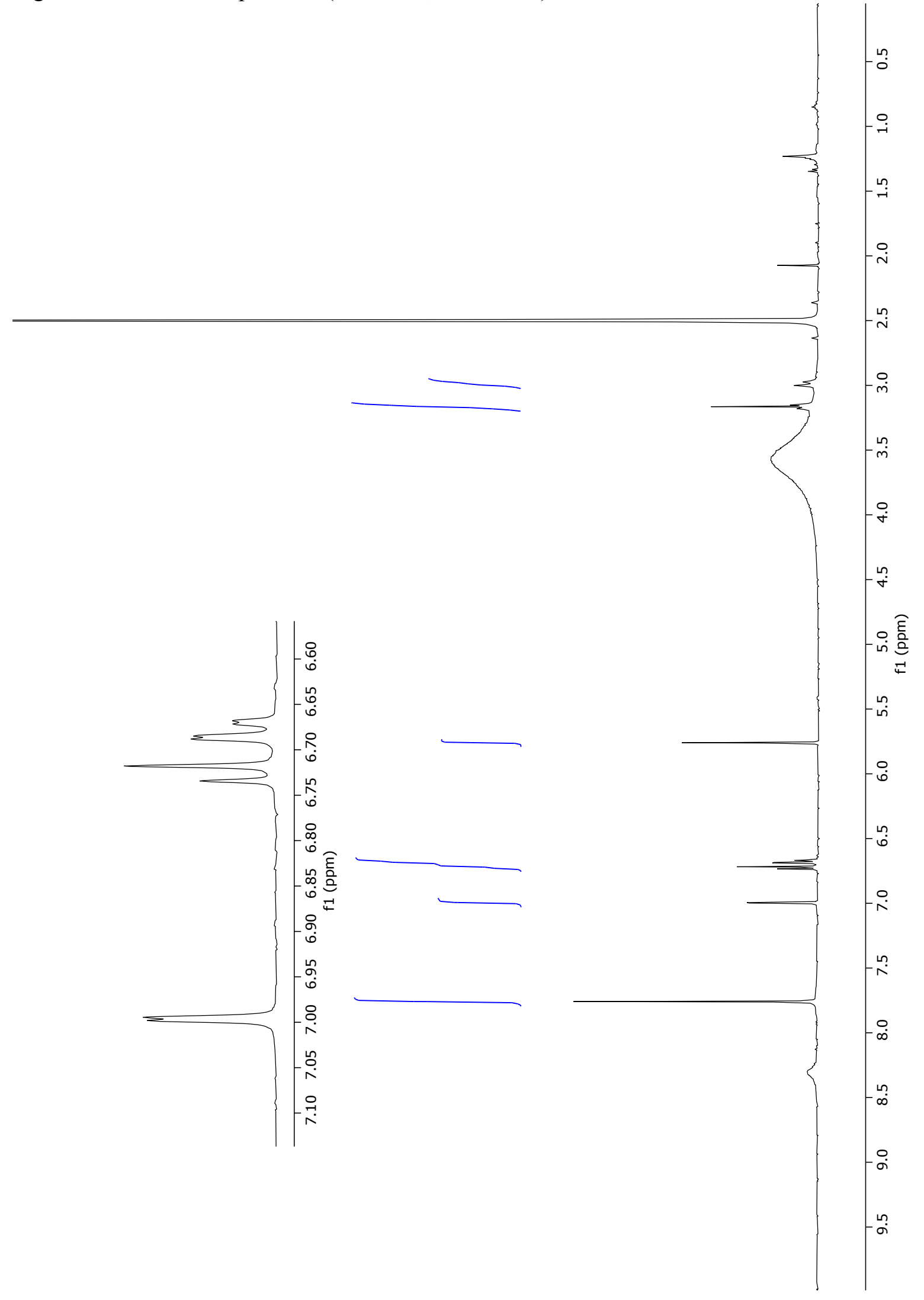


Figure S11: COSY NMR spectrum (600 MHz, DMSO-d $\left.\mathrm{d}_{6}\right)$ of 5

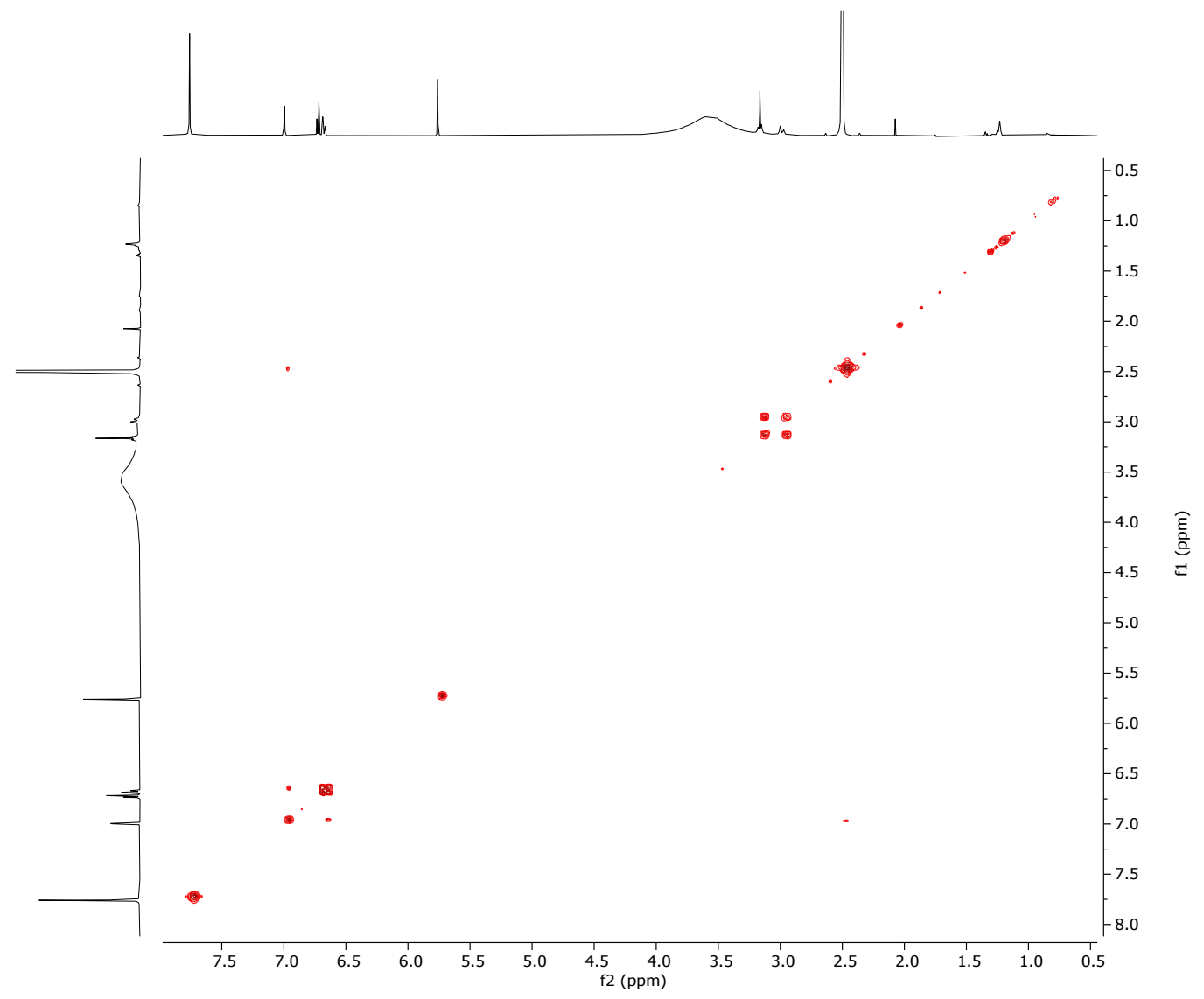

Figure S12: HMBC NMR spectrum (600 MHz, DMSO-d $\left.{ }_{6}\right)$ of 5

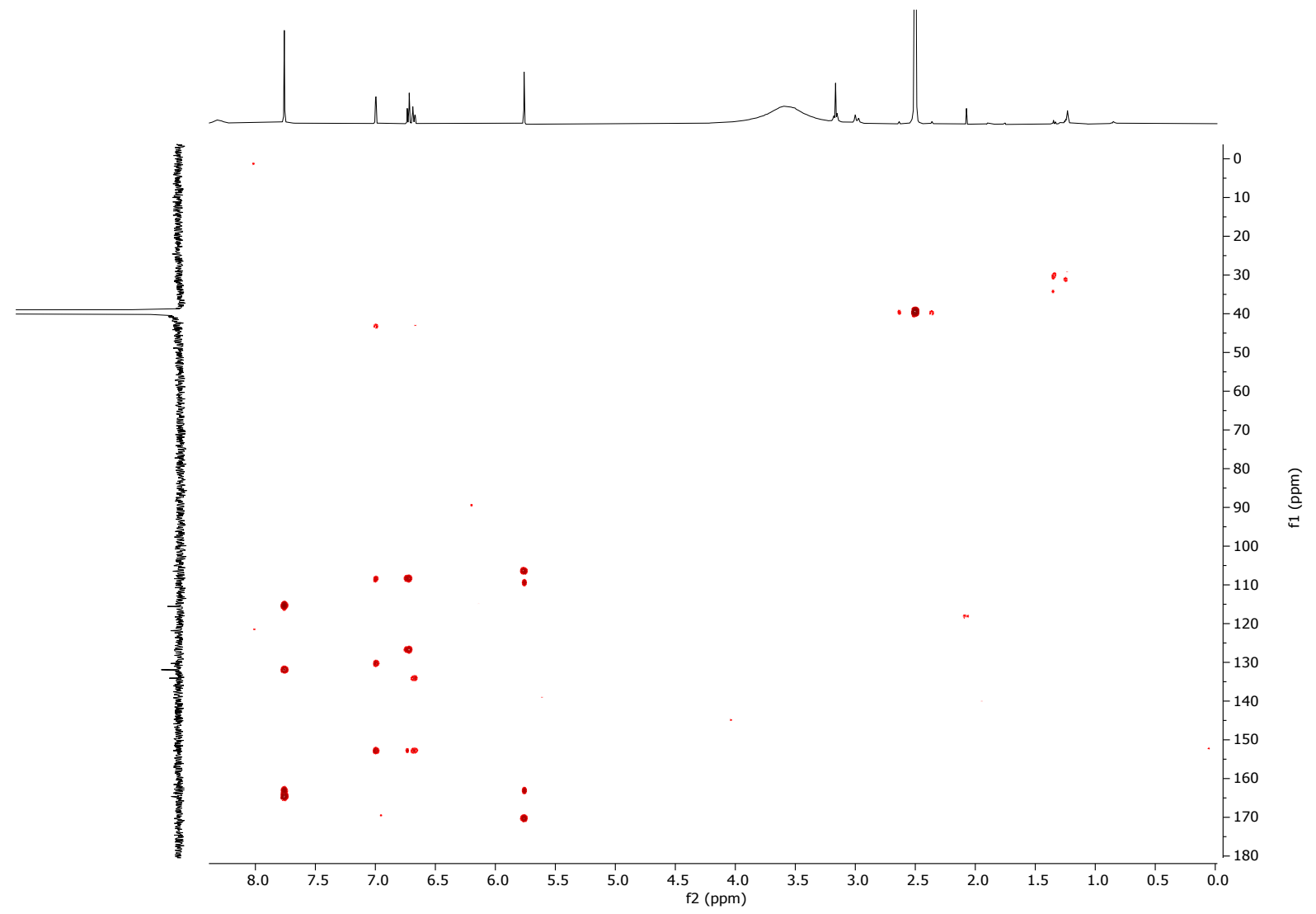


Figure S13: HSQC NMR spectrum (600 MHz, DMSO-d $\left.\mathrm{d}_{6}\right)$ of 5

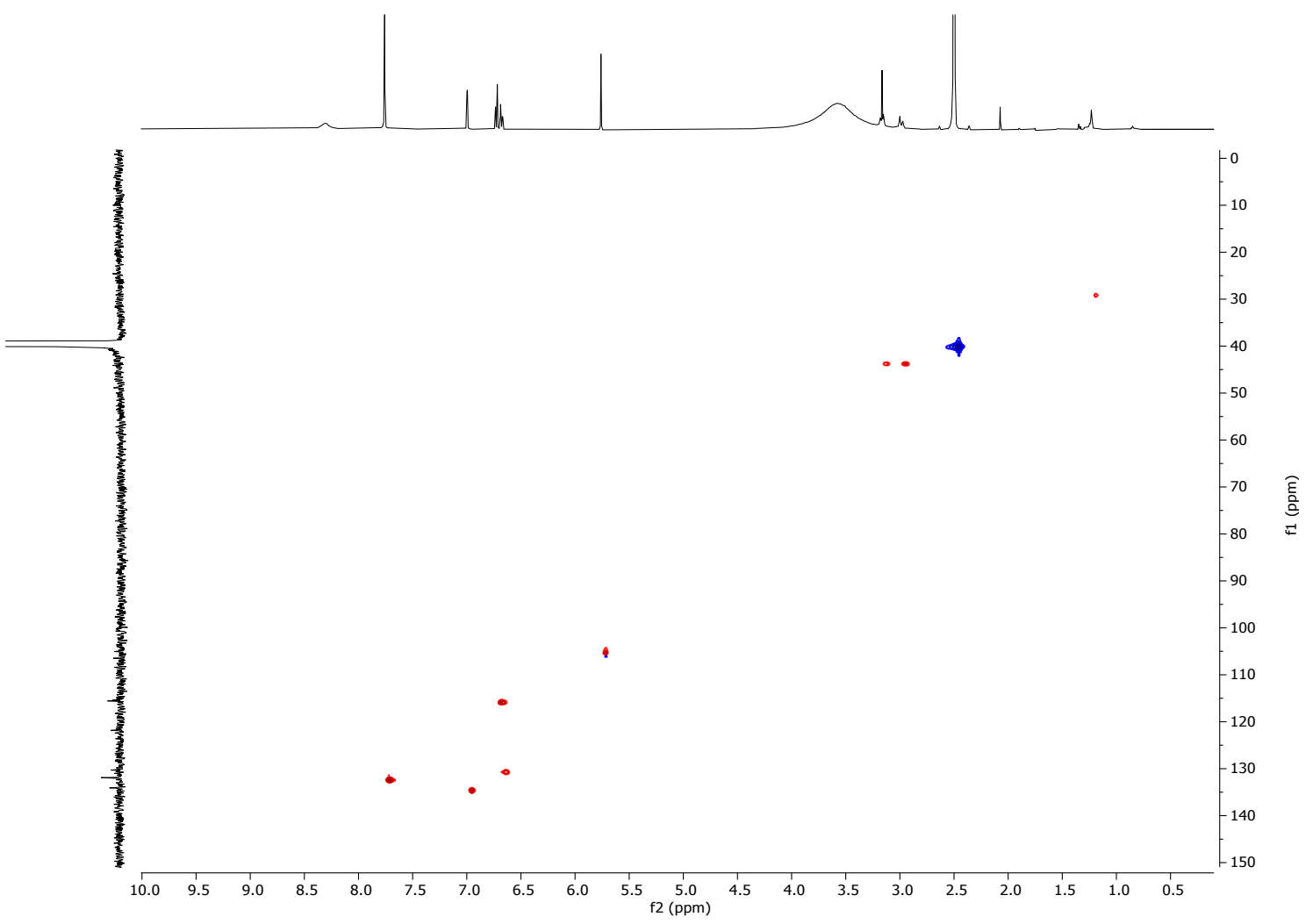

Figure S14: HRESIMS of 5
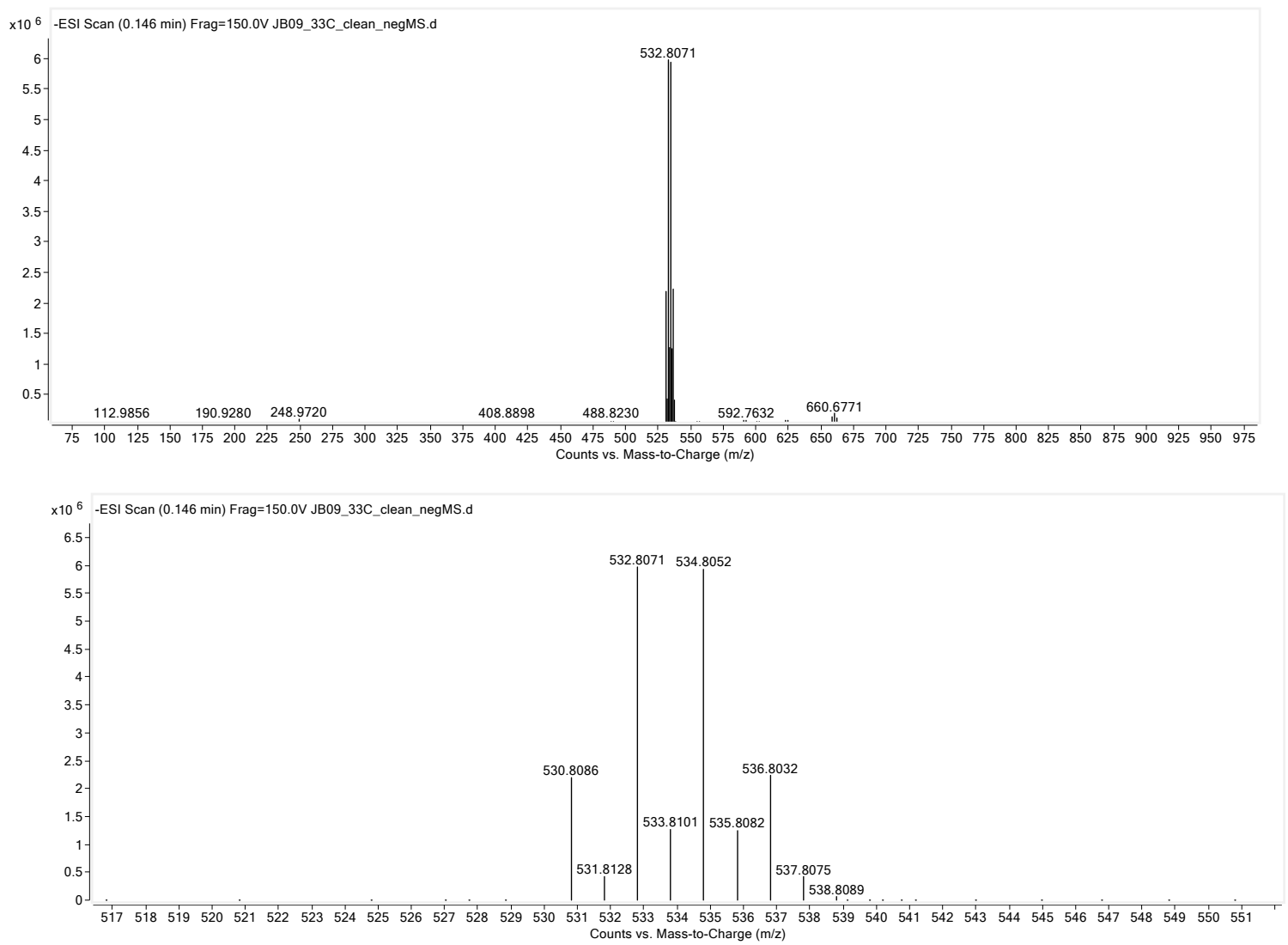
Figure S15: HRESIMS/MS of 5

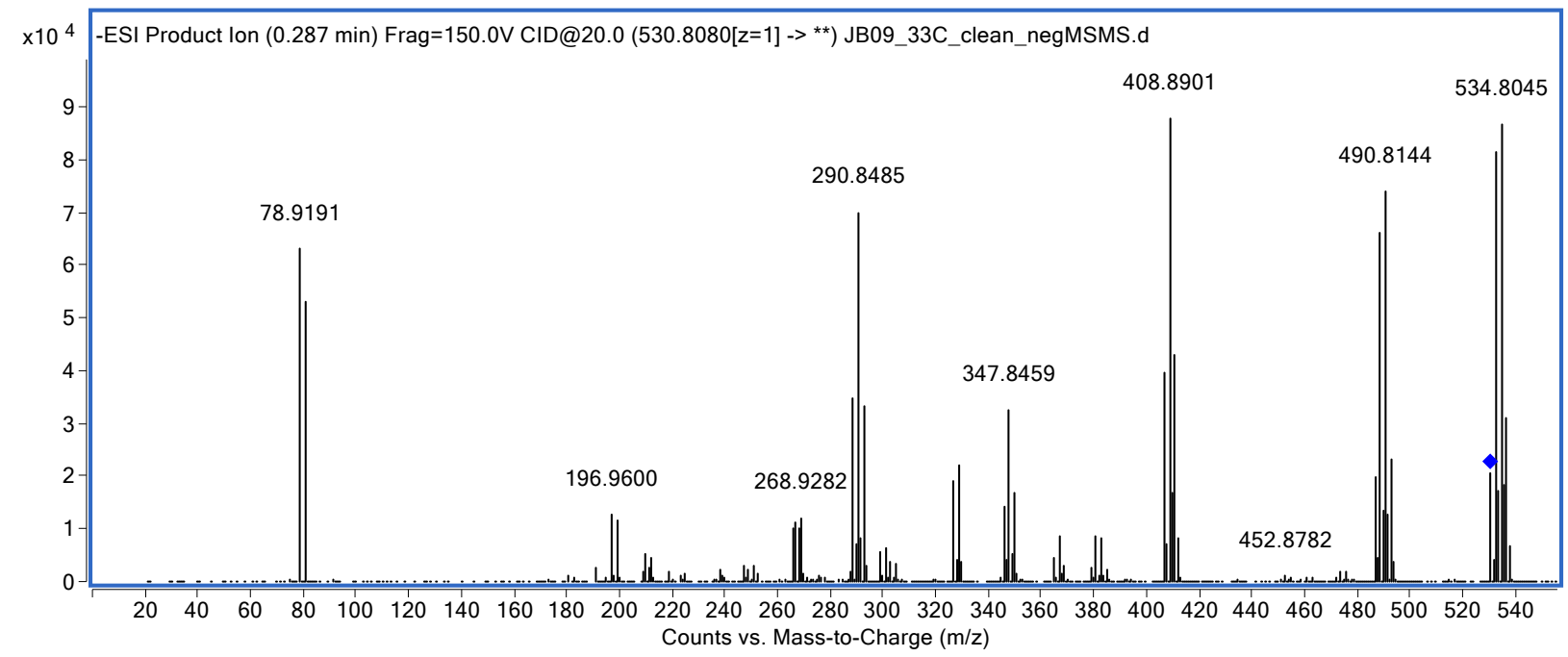

Figure S16: UV/Vis spectrum of 5

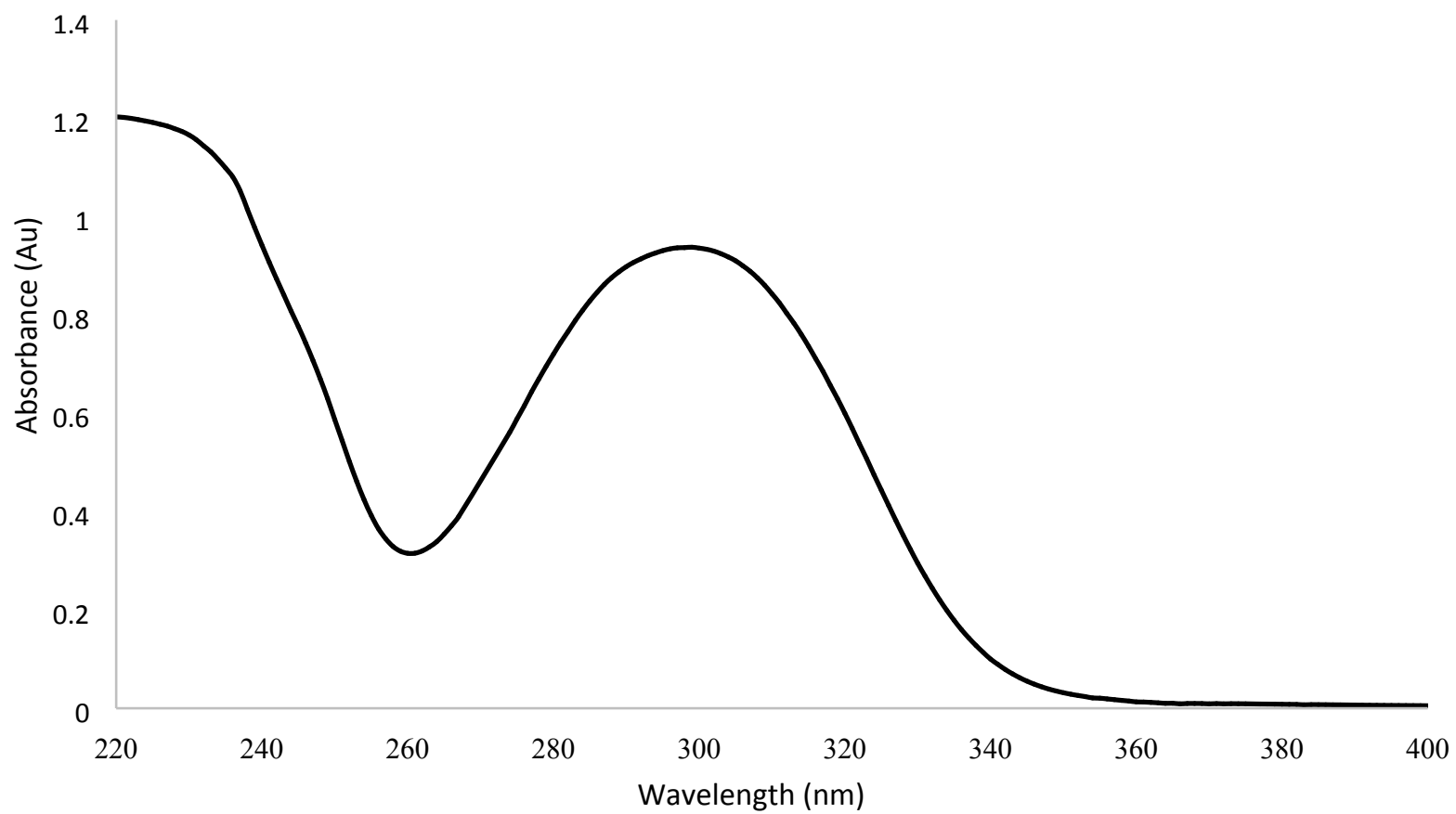


Figure S17: ${ }^{1} \mathrm{H}$ NMR spectrum $\left(600 \mathrm{MHz}, \mathrm{DMSO}-\mathrm{d}_{6}\right)$ of 6

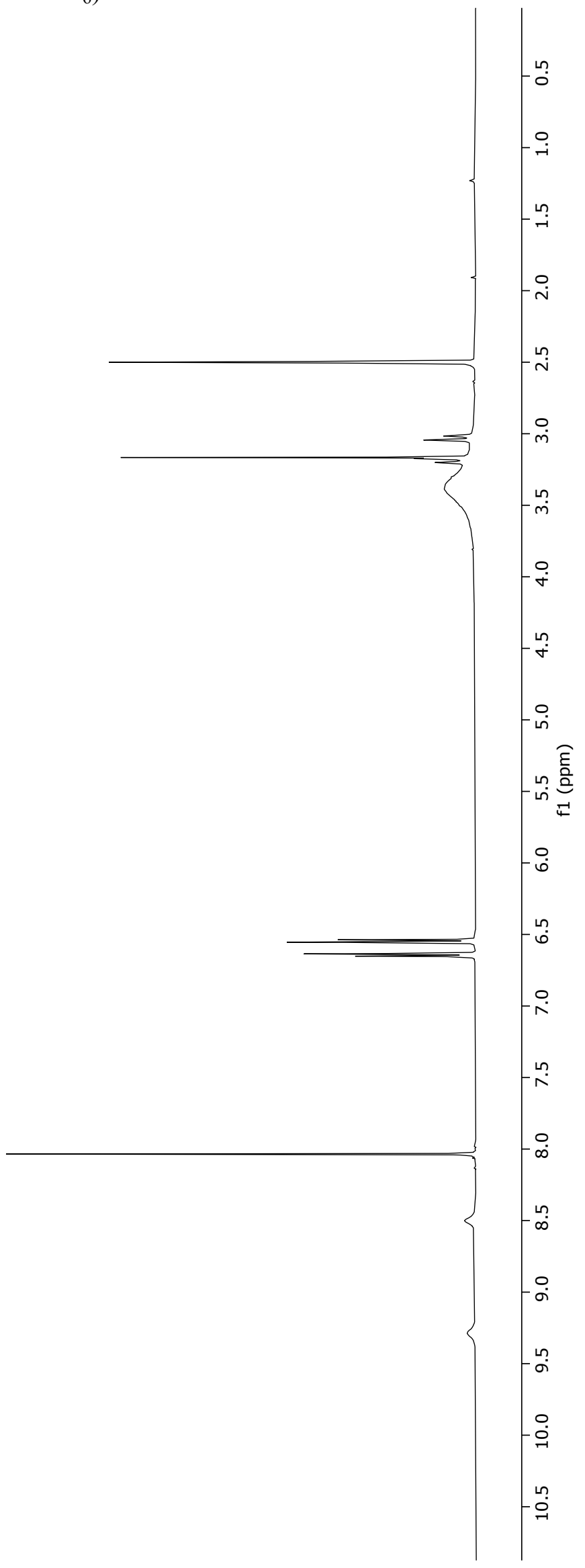


Figure S18: ${ }^{13} \mathrm{C}$ NMR spectrum $\left(150 \mathrm{MHz}, \mathrm{DMSO}-\mathrm{d}_{6}\right)$ of 6

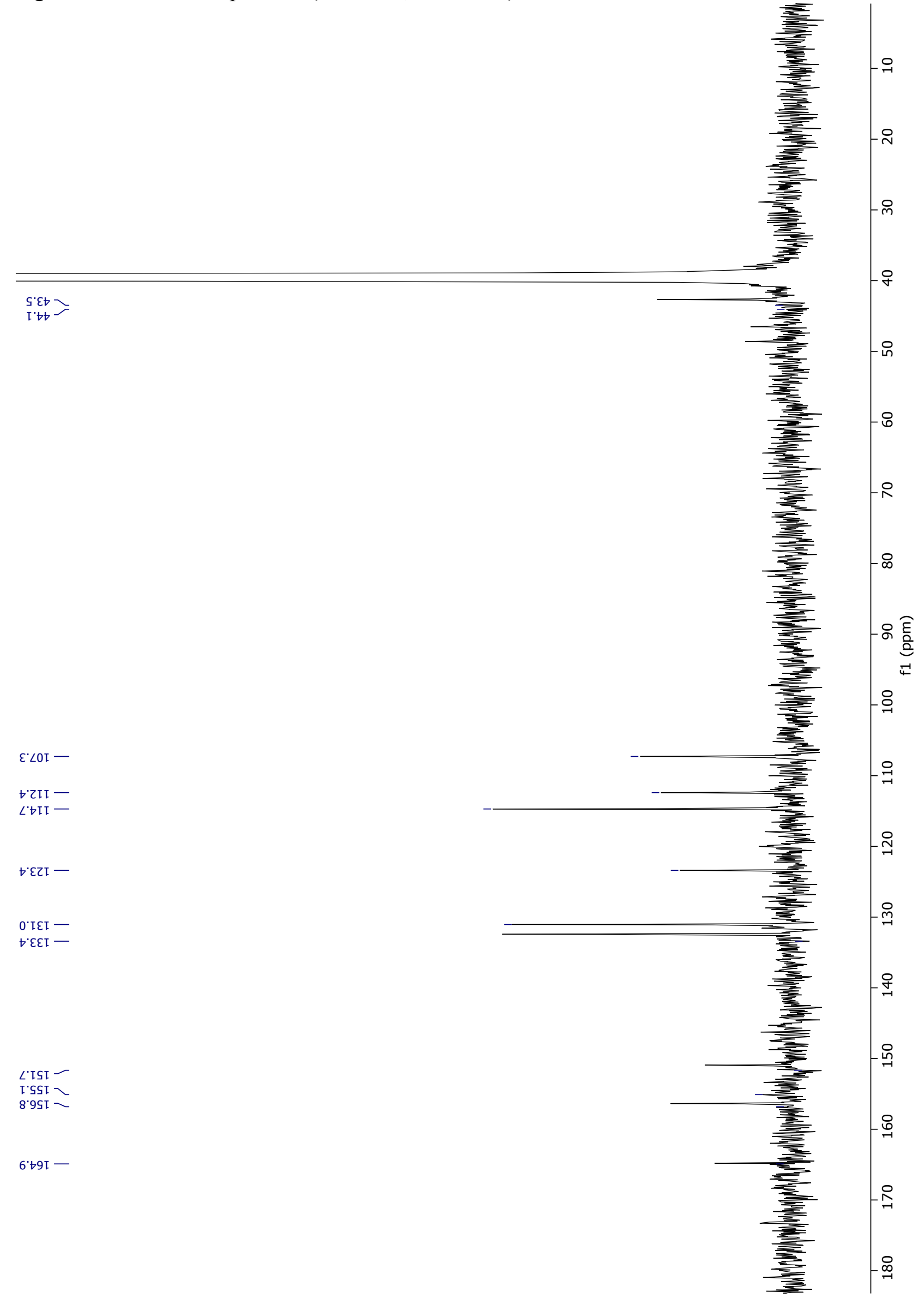


Figure S19: COSY NMR spectrum (600 MHz, DMSO-d $\left.\mathrm{d}_{6}\right)$ of 6

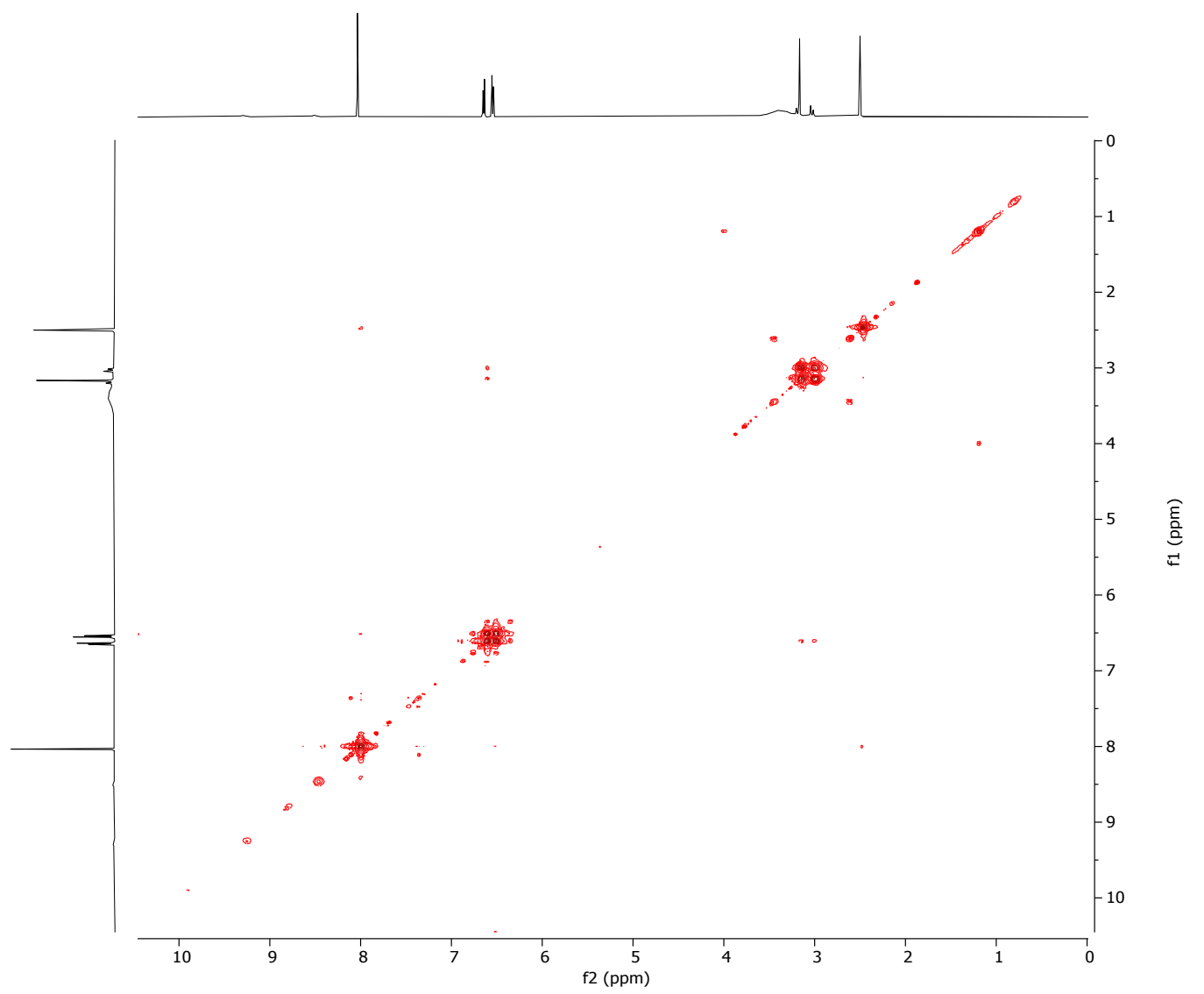

Figure S20: HMBC NMR spectrum (600 MHz, DMSO-d $\left.{ }_{6}\right)$ of 6

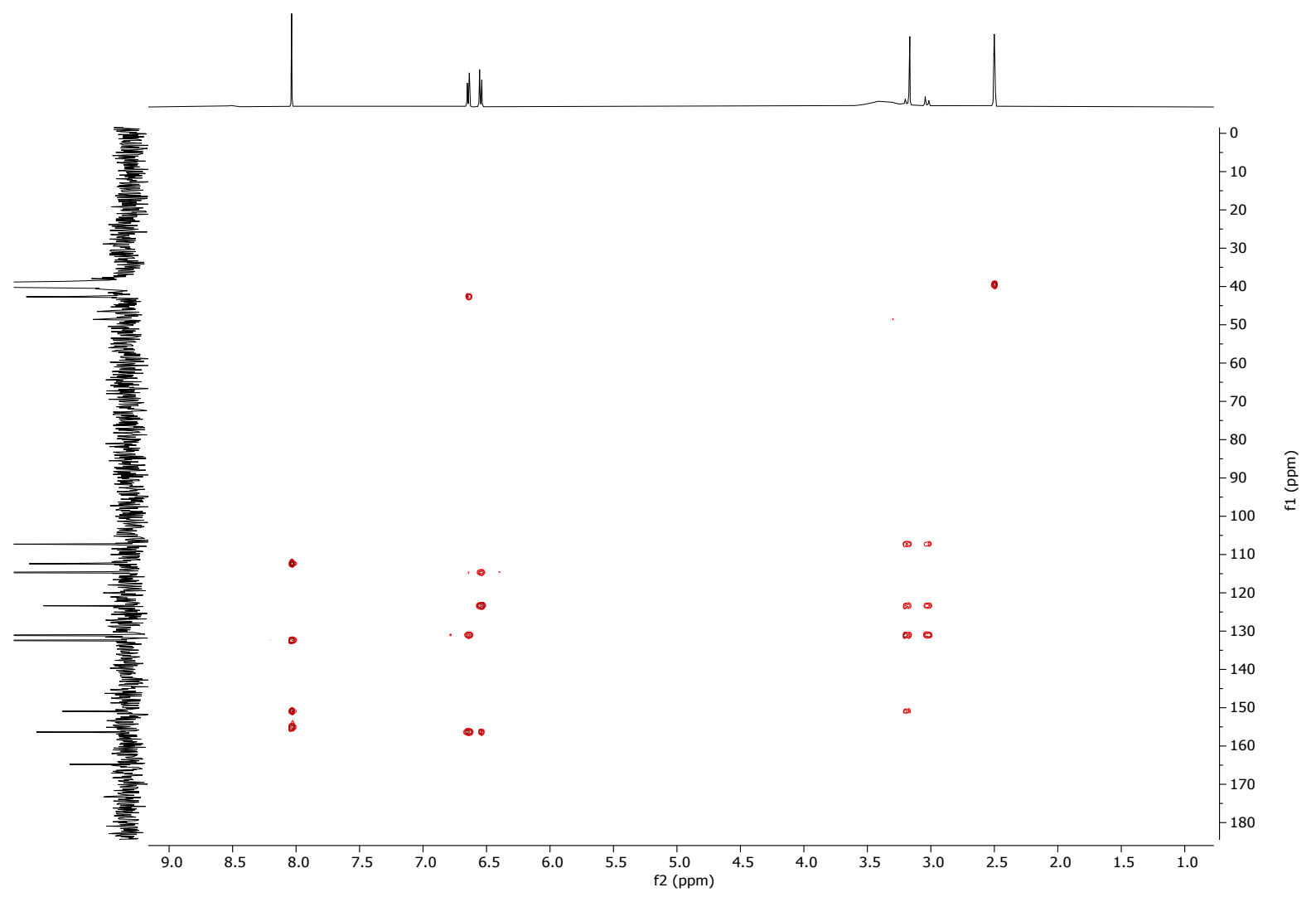


Figure S21: HSQC NMR spectrum (600 MHz, DMSO-d $\left.\mathrm{d}_{6}\right)$ of 6

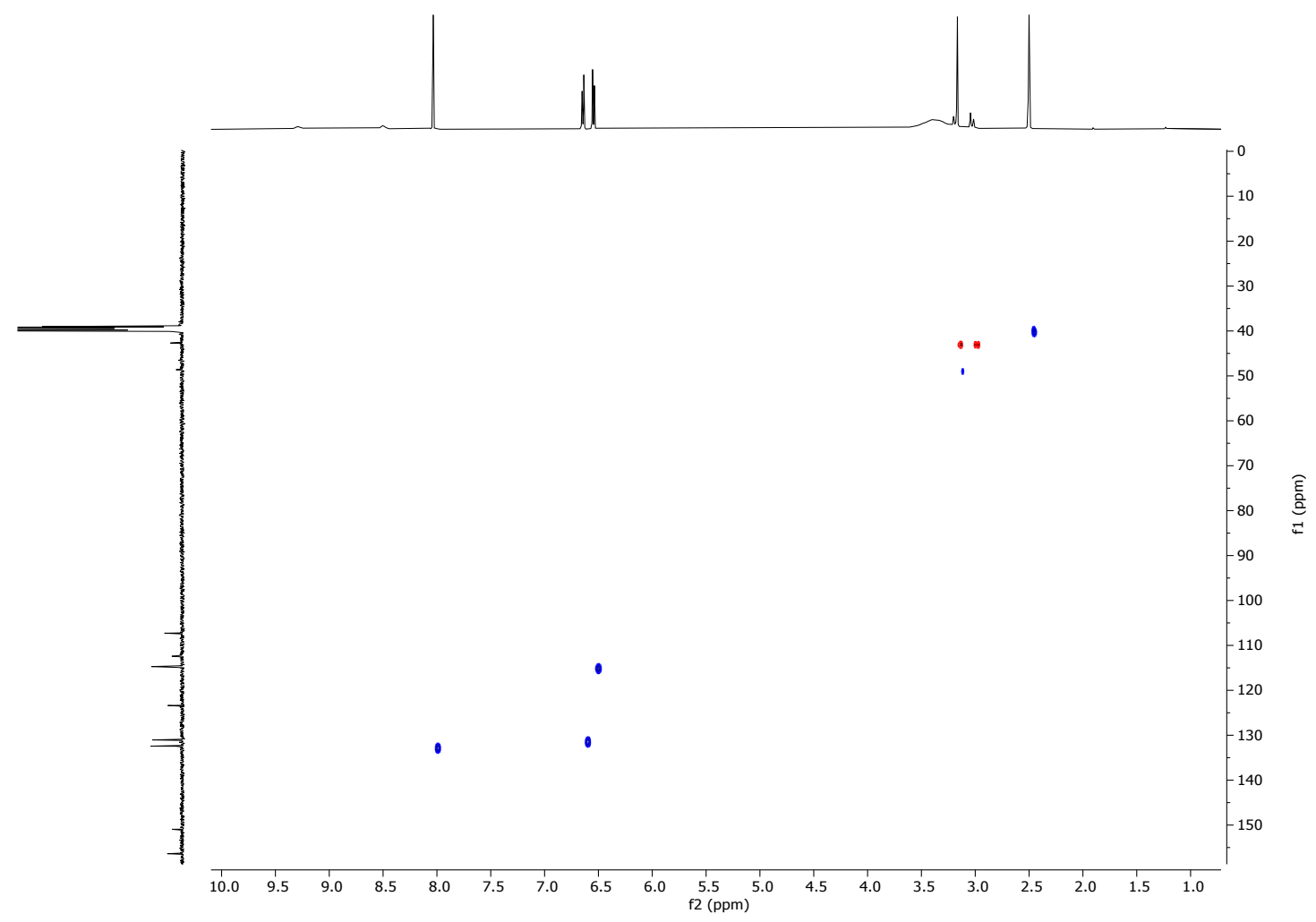

Figure S22: HRESIMS of 6

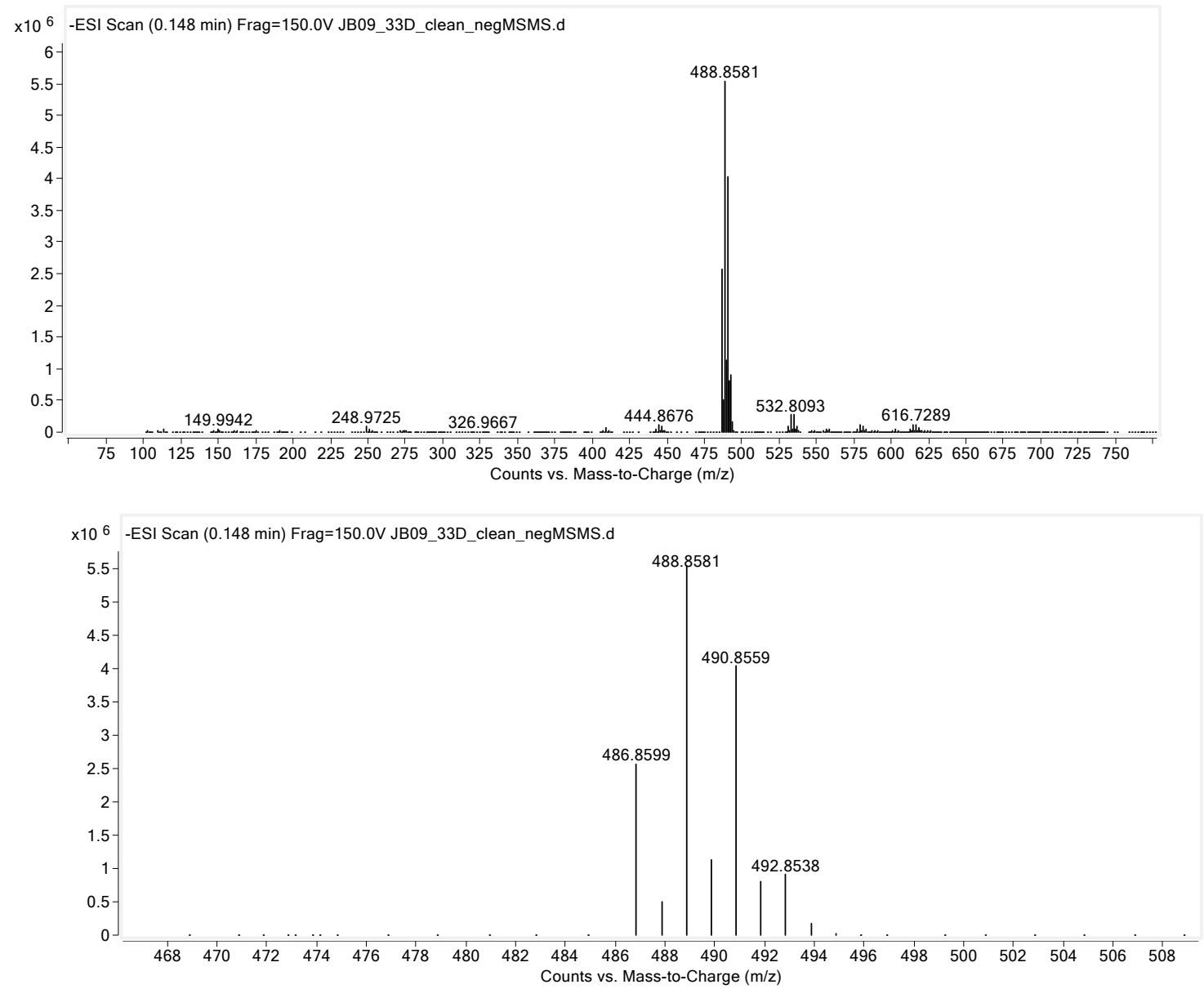


Figure S23: HRESIMS/MS of 6

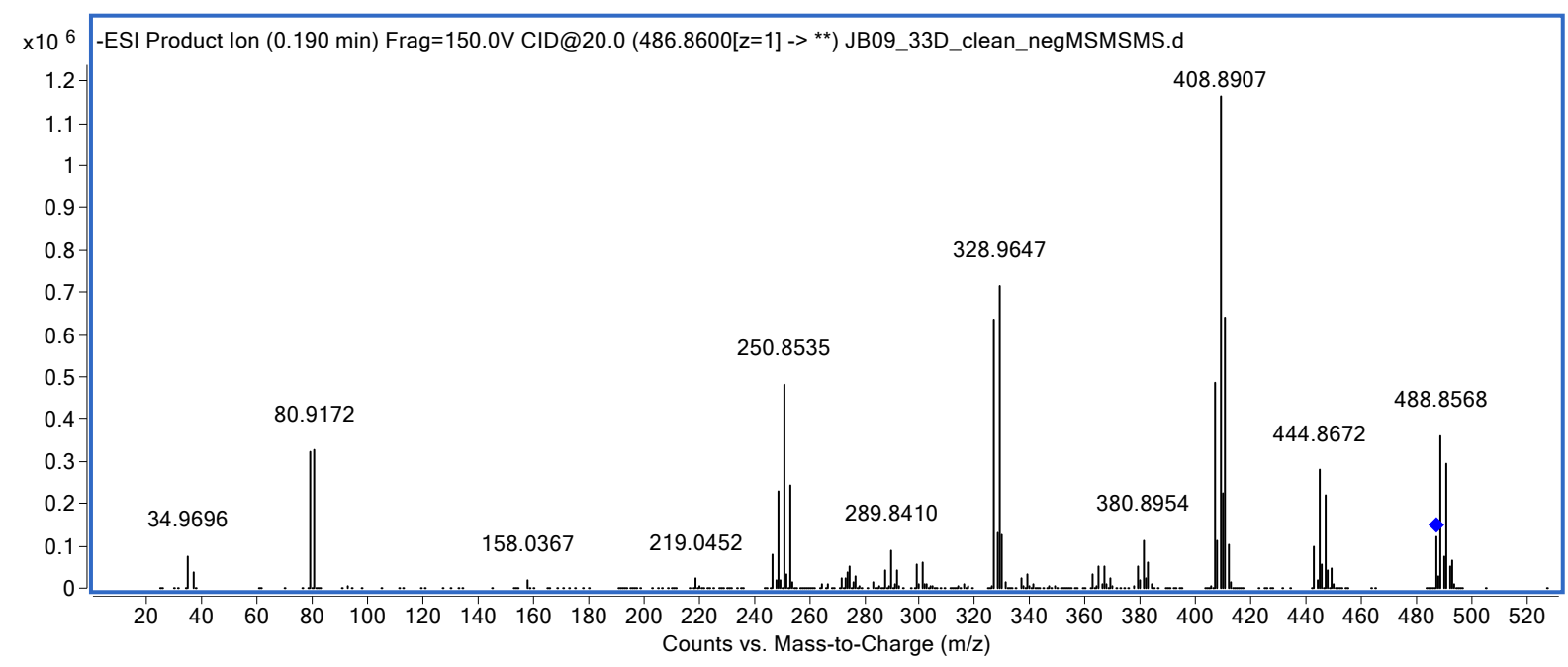

Figure S24: UV/Vis spectrum of 6

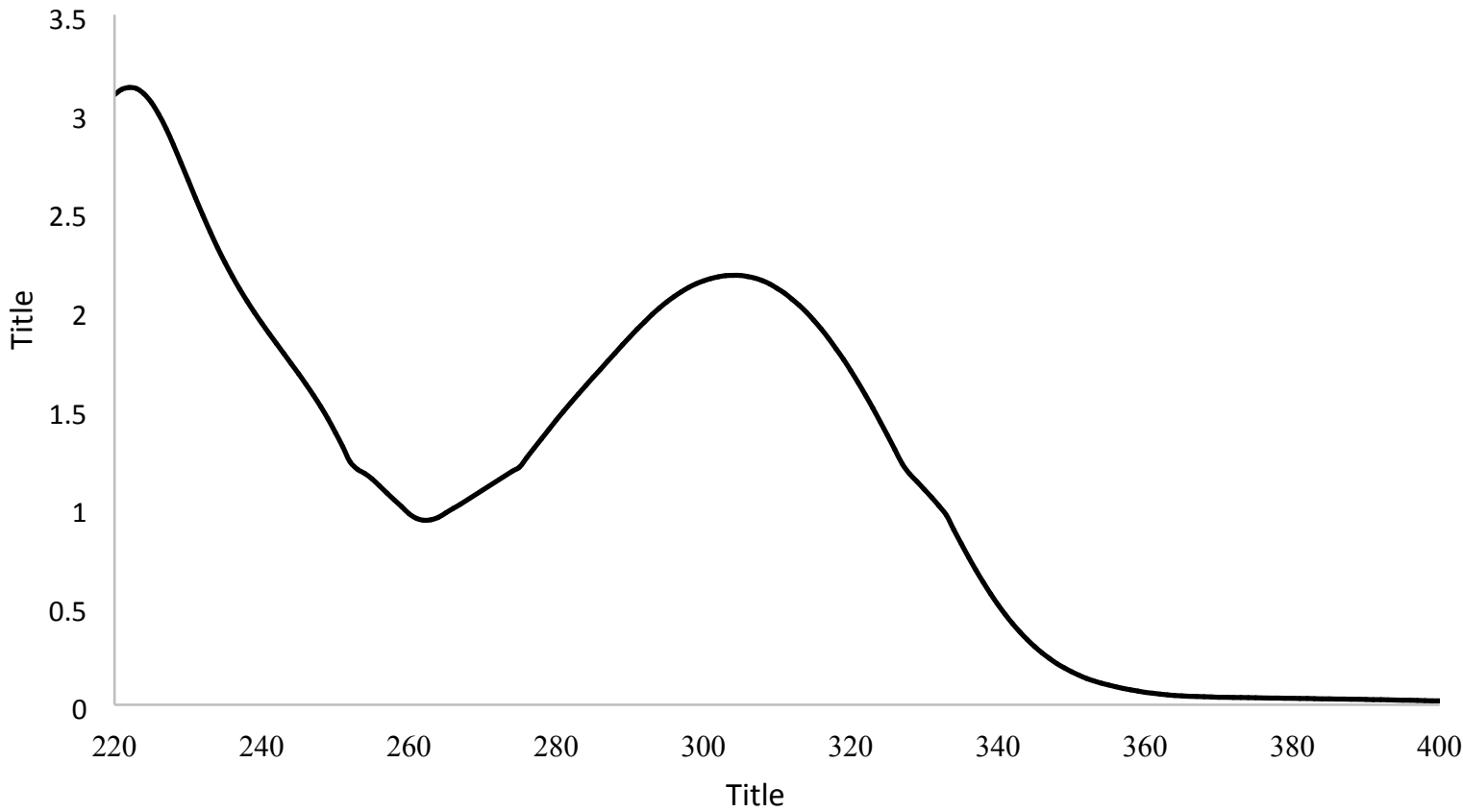


Table S1 - $\mathrm{IC}_{50}$ values for compounds 3, 5-7 and mithramycin A (positive control) against HCT -116 cells.

\begin{tabular}{cccccc}
\hline & & \multicolumn{5}{c}{$\mathrm{IC}_{50}(\mathrm{nM})$} \\
Compound & Rep 1 & Rep 2 & Rep 3 & Average & Std Dev \\
\hline \multirow{2}{*}{3} & $>12500$ & $>30000$ & $>12500$ & & \\
& $>12500$ & $>30000$ & $>12500$ & & \\
$\mathbf{5}$ & 11469.1 & 13603.8 & 12290.3 & 12818.1 & 1108.4 \\
& 12208.7 & 14565.5 & 12771 & & \\
$\mathbf{6}$ & $>12500$ & $>30000$ & $>12500$ & & \\
& $>12500$ & $>30000$ & $>12500$ & & \\
7 & $>12500$ & $>30000$ & $>12500$ & & 3.7 \\
\hline
\end{tabular}

